\title{
$\beta$-catenin-independent WNT signaling and Ki67 in contrast to the estrogen receptor status are prognostic and associated with poor prognosis in breast cancer liver metastases
}

\author{
Annalen Bleckmann ${ }^{1,2} \cdot$ Lena-Christin Conradi $^{3} \cdot$ Kerstin Menck $^{1}$ • \\ Nadine Annette Schmick ${ }^{1}$ - Antonia Schubert ${ }^{1} \cdot$ Eva Rietkötter $^{1} \cdot$ Jetcy Arackal $^{1}$ . \\ Peter Middel $^{4} \cdot$ Alexandra Schambony $^{5}$ - Torsten Liersch ${ }^{3} \cdot$ Kia Homayounfar $^{3}$. \\ Tim Beißbarth ${ }^{2} \cdot$ Florian Klemm $^{1}$ - Claudia Binder ${ }^{1}$ - Tobias Pukrop ${ }^{1,6}$
}

Received: 3 April 2015/Accepted: 1 February 2016/Published online: 9 February 2016

(c) The Author(s) 2016. This article is published with open access at Springerlink.com

\begin{abstract}
Liver metastasis development in breast cancer patients is common and confers a poor prognosis. So far, the prognostic significance of surgical resection and clinical relevance of biomarker analysis in metastatic tissue have barely been investigated. We previously demonstrated an impact of WNT signaling in breast cancer brain metastasis. This study aimed to investigate the value of established prognostic markers and WNT signaling components in liver metastases. Overall $\mathrm{N}=34$ breast cancer liver metastases (with matched primaries in 19/34 cases)
\end{abstract}

Annalen Bleckmann and Lena-Christin Conradi contributed equally to this work.

Electronic supplementary material The online version of this article (doi:10.1007/s10585-016-9780-3) contains supplementary material, which is available to authorized users.

Tobias Pukrop

tobias.pukrop@klinik.uni-regensburg.de;

tobias.pukrop@ukr.de

1 Department of Hematology/Medical Oncology, University Medical Center Göttingen, 37099 Göttingen, Germany

2 Department of Medical Statistics, University Medical Center Göttingen, 37099 Göttingen, Germany

3 Department of General, Visceral and Pediatric Surgery, University Medical Center Göttingen, 37099 Göttingen, Germany

4 Institute of Pathology, University Medical Center Göttingen, 37099 Göttingen, Germany

5 Department Biology, Developmental Biology, FriedrichAlexander University Erlangen-Nürnberg, 91058 Erlangen, Germany

6 Clinic for Internal Medicine III, Hematology and Medical Oncology, University Regensburg, 93053 Regensburg, Germany were included in this retrospective study. Primaries and metastatic samples were analyzed for their expression of the estrogen (ER) and progesterone receptor, HER-2, Ki67, and various WNT signaling-components by immunohistochemistry. Furthermore, $\beta$-catenin-dependent and -independent WNT scores were generated and analyzed for their prognostic value. Additionally, the influence of the alternative WNT receptor ROR on signaling and invasiveness was analyzed in vitro. ER positivity (HR $0.09,95 \%$ CI 0.01-0.56) and high Ki67 (HR 3.68, $95 \%$ CI 1.12-12.06) in the primaries had prognostic impact. However, only Ki67 remained prognostic in the metastatic tissue (HR 2.46, $95 \%$ CI 1.11-5.44). Additionally, the $\beta$-catenin-independent WNT score correlated with reduced overall survival only in the metastasized situation (HR 2.19, $95 \%$ CI $1.02-4.69, p=0.0391)$. This is in line with the in vitro results of the alternative WNT receptors ROR1 and ROR2, which foster invasion. In breast cancer, the value of prognostic markers established in primary tumors cannot directly be translated to metastases. Our results revealed $\beta$ catenin-independent WNT signaling to be associated with poor prognosis in patients with breast cancer liver metastasis.

Keywords Breast cancer - Metastasis - WNT signaling · Prognostic score

$\begin{array}{ll}\text { Abbreviations } \\ \text { ER } & \text { Estrogen receptor } \\ \text { OS } & \text { Overall survival } \\ \text { NSCLC } & \text { Non-small cell lung cancer } \\ \text { EMT } & \text { Epithelial mesenchymal transition } \\ \text { LEF/TCF } & \text { Lymphoid enhancer factor/T cell factor } \\ \text { MET } & \text { Mesenchymal epithelial transition } \\ \text { RTK } & \text { Receptor tyrosine kinases }\end{array}$




$\begin{array}{ll}\text { JNK } & \text { Jun-N-terminal kinase } \\ \text { Fz } & \text { Frizzled } \\ \text { DVL } & \text { Dishevelled } \\ \text { WNT/ } & \text { WNT/planar cell polarity pathway } \\ \text { PCP } & \\ \text { PGR } & \text { Progesterone receptor } \\ \text { HER-2 } & \text { Erb-b2 receptor tyrosine kinase } \\ \text { FFPE } & \text { Formalin-fixed paraffin-embedded } \\ \text { IHC } & \text { Immunohistochemistry } \\ \text { UICC } & \text { Union Internation Contre le Cancer } \\ \text { C/S-ISH } & \text { Chromogene or silver in situ hybridization } \\ \text { HER-3 } & \text { Erb-b3 receptor tyrosine kinase } \\ \text { NRG1/2 } & \text { Neuregulin 1/2 } \\ \text { ROR1/2 } & \text { Receptor tyrosine kinase-like orphan receptor }\end{array}$

\section{Introduction}

The 5-year overall survival (OS) for breast cancer patients in Europe increased over time from $78.4 \%$ (1999-2001) to $82.4 \%$ (2005-2007) owing to the availability of more efficient treatment modalities nowadays [1]. However, the overall survival decreases dramatically to only $2-3$ years for patients on diagnosis of distant metastasis [2]. Besides bone, the liver is the most frequent site of breast cancer metastasis with an incidence of $40-50 \%$ of all metastasized patients [3]. Nevertheless, resection of isolated breast cancer liver metastases is still a controversial topic of discussion. However, this locoregional treatment is a well-established approach in a multimodal therapeutic concept for patients with metastasized colorectal cancer [3-8]. Probable reasons for this controversial debate are the diversity of the metastatic pattern in different organs, the lack of prognostic biomarkers in this situation, and the heterogeneity of breast cancer. The pattern of organ metastasis is partially determined by features of the primary tumor cells $[9,10]$. For example, hormone-receptor-positive breast carcinoma cells rather metastasize into bone tissue, while triple-negative breast cancer cells initially spread to other solid organs, such as the liver for example. A number of molecular characteristics in the carcinoma cells have already been identified for this organo-tropism $[9,11]$. Furthermore, the last steps of metastasis in host organs, such as colonization and macroscopic outgrowth, are influenced by the unique environments of the target organs of metastasis [12].

Recent genomic analyses of primary tumors in comparison to metastatic tissue indicated that the first steps of metastasis including seeding into distant organs are early events and thus the metastatic cells appear to go through an evolutionary process in parallel to the primary tumor (parallel progression or branched evolution) [13-16].
Fortunately, many seeded carcinoma cells undergo apoptosis in the microenvironment of the foreign host organ and only few carcinoma cells colonize successfully [17-20]. Thus, the final steps of metastasis are the most vulnerable and least effective during this process and are massively influenced by its own genetic evolution and the specific metastatic microenvironment.

We recently demonstrated in breast cancer with brain metastasis that the local defense system of the brain, composed of astrocytes and microglia, attempts to combat the epithelial carcinoma cells foreign to the brain. This glial attack leads to apoptosis in some cancer cells. However, during this defense program the carcinoma cells also benefit from molecules secreted by the microenvironment that enhance their invasion. Further analysis revealed that WNT signaling is involved in this glia-induced carcinoma cell invasion during colonization of the brain tissue, indicating some brain-specific activation of WNT [18, 21]. In addition, immunohistochemistry of brain metastases of non-small cell lung cancer (NSCLC) [22] and breast cancer [23] confirmed the role of WNT signaling in macroscopically established brain metastases. However, both evaluations indicated an important role for components of the $\beta$ catenin-independent WNT pathway. Comparable paracrine WNT activation of colonizing carcinoma cells by the metastatic microenvironments at other sites is likely; however this has not been analyzed systematically.

The involvement of WNT signaling in the process of metastasis is not unexpected, since the WNT pathways regulate important events such as tumor initiation, carcinoma cell migration/invasion, epithelial mesenchymal transition (EMT), angiogenesis, lymphangiogenesis, and wound healing. In addition, WNT components are significantly involved in many embryonic development processes [24-26]. Interestingly, in individual developmental steps, for example during heart development, it is necessary that phases of active WNT signals are interchanged by phases of WNT inhibition in a specific time sequence [27]. Certain parallels may be assumed for metastasis. In the early metastatic steps, the cancer cells perform an EMT-like process known to be governed by active $\mathrm{WNT} / \beta$-catenin signaling. Briefly, EMT includes, among others, the downregulation of E-cadherin, the activation and translocation of $\beta$-catenin into the nucleus. There it regulates the WNT/ $\beta$-catenin target genes as a co-transcription factor together with the transcription factors of the lymphoid enhancer factor/T cell factor (LEF/TCF) family. However, in the distant organ, the reverse process of EMT-mesenchymal epithelial transition (MET) - is presumed to take place. A recent study demonstrated the repression of the EMT inducer Prrx1 as a mandatory prerequisite for successful metastatic colonization of the lung [28] and that up-regulation of E-cadherin could accelerate this colonization by 
improving the intercellular exchange of growth factors between the metastatic carcinoma cells [29]. Moreover, in contrast to colon cancer cell lines in breast cancer cells the $\mathrm{WNT} / \beta$-catenin activity is low to not measurable [30-32].

For these reasons, it is not unexpected that alternative WNT signals suppressing WNT/ $\beta$-catenin-signaling are detected in breast cancer as well as during the final steps of metastasis in distant organs. Our recent studies of human brain parenchyma colonization and metastasis revealed overexpression of WNT5a/b, ROR1/ROR2, increased activity of WNT/c-Jun and not active $\beta$-catenin [23]. ROR1/ROR2 belong to the receptor tyrosine kinases (RTK) and are activated by the binding of WNT5a [33, 34]. The activation of the kinase domain leads to Jun-N-terminal kinase (JNK) and subsequent c-Jun activation. Interestingly, WNT5a/ROR1/ROR2-dependent signaling can also lead to WNT/ $\beta$-catenin inhibition. Additionally, the ligand WNT5a can also act through Frizzled (Fz) receptors and the phosphoprotein dishevelled (DVL), ultimately activating the so-called WNT/planar cell polarity pathway (WNT/PCP) [35, 36]. WNT/PCP signaling is very important in the organization of tissue polarity, ensuring the correct orientation of a single epithelial cell within the organization and function of the whole tissue. Thus it is not surprising that components of the WNT/PCP pathway are aberrantly overexpressed during the establishment of malignant epithelial tissue in hitherto unforeseen organs.

Taken together, it may be assumed that the biological features of the carcinoma cells, including their WNT activity, have to change during the various steps of metastasis to allow successful adjustment to the current conditions/microenvironment, otherwise the carcinoma cells will undergo apoptosis. In accordance with these assumptions, clinical and pathological scores, determined in the tissue of the primary tumor, cannot simply be transferred to the metastatic tissue. However, pathological scoring systems relate almost solely on studies of the primary tumor tissues such as the most prominent predictive markers in breast cancer, the estrogen receptor (ER), the progesterone receptor (PGR) and the erb-b2 receptor tyrosine kinase (HER-2) status. Furthermore, the triple-negative subtype has a negative prognostic impact. Additionally, the proliferation status quantified by Ki67 is also of prognostic value. Again, these markers are mostly determined in the primary tumor and their prognostic capacity determined in metastatic tissue remains poorly defined. This can be attributed to the fact that the clinical routine in breast cancer patients does not include metastatic surgery or biopsy of the metastatic tissue and thus the availability of matched tissue samples of the primary tumor and metastatic tissue derived thereof is rare.

Thus, the aim of this study was to investigate the value of established prognostic markers (such as ER, PGR, HER-2) and WNT components in liver metastases of breast cancer and matched primaries. This work is based on in vitro data analyzing the effects on signaling and invasion of $\beta$-catenin-independent WNT signaling via the alternative WNT receptor ROR.

\section{Materials and methods}

\section{Cell lines and cell culture}

If not indicated otherwise, all reagents and chemicals were purchased from Sigma (Munich, Germany). The human breast cancer cell lines MCF-7, MDA-MB-231 and SKBR-3 were obtained from the American Type Culture Collection (ATCC, Rockville, USA) and were cultured in RPMI-1640 media (PAA, Cölbe, Germany) supplemented with $10 \%$ fetal bovine serum (FCS; Sigma, Munich, Germany).

\section{Knockdown and overexpression}

To generate ROR1 shRNA lentiviral particles, HEK293T cells (ATCC) were co-transfected with the packaging plasmids pMD2.G (Addgene plasmid: 12259) and pCMV $\Delta$ R8.2 (Addgene plasmid: 12263, both provided by Didier Trono, École Polytechnique Fédérale de Lausanne, Laboratory of Virology and Genetics, Lausanne, Switzerland) and either the pGIPZ non-silencing control (ns ctl) shRNA or shROR1 plasmid (Thermo Scientific, Schwerte, Germany) through calcium phosphate precipitation. While the ns ctl sequence is proprietary, the mature ROR1 targeting sequence is $5^{\prime}$-ATTTATAGGATCTGCCATG- $3^{\prime}$. Virus-containing supernatants were concentrated using lentiviral enrichment reagent (MobiTech, Göttingen, Germany) and viral titers were calculated based upon the GFP expression of HEK293T transduced with serial dilutions of the shRNA of interest. MDA-MB-231 cells were finally transduced with a multiplicity of infection of 5.0. Cells were selected in medium with $2 \mu \mathrm{g} / \mathrm{mL}$ puromycin (Sigma, Munich, Germany).

For ROR2 overexpression, the plasmids pcDNA 3.1/ $\mathrm{Zeo}(+)$ (Invitrogen, Paisley, UK) and pcDNA-hsROR2 were introduced into MCF-7 and SK-BR-3 cells using the Nanofectin transfection reagent (PAA, Cölbe, Germany). Stable expression was achieved by selecting for zeomycin $(100 \mu \mathrm{g} / \mathrm{ml})$ resistance.

\section{RNA isolation and qRT-PCR}

RNA was isolated using the High Pure RNA isolation kit (Roche, Mannheim, Germany). Reverse transcription was accomplished with the iScript Master Mix (BioRad, 
Munich, Germany). QRT-PCR was performed using SYBR green detection with mRNA-specific primers (Supplemental Table 1) on the ABI PRISM 7900HT system (Applied Biosystems, Darmstadt, Germany). Gene expression was analyzed with SDS, software version 2.4 (Applied Sciences) and normalized to the two housekeeping genes GNB2L1 and HPRT1.

\section{Sub-cellular fractionation, protein lysis, immunoprecipitation, and immunoblot}

To analyze the sub-cellular localization of our proteins of interest, cytosolic and nuclear fractions of cells were isolated as follows: after washing in PBS, cells were resuspended in cold hypotonic buffer (10 mM HEPES, pH 7.9, $1.5 \mathrm{mM} \mathrm{MgCl} 2,10 \mathrm{mM} \mathrm{KCl}, 0.5 \mathrm{mM}$ DTT) and lysed by the addition of $0.5 \%(\mathrm{v} / \mathrm{v})$ Nonidet P-40, vortexed and centrifuged at $750 \mathrm{~g}$ for $1 \mathrm{~min}$ at $4{ }^{\circ} \mathrm{C}$. The resulting supernatant was then collected as the cytosolic extract. The remaining pellet was resuspended in extraction buffer (20 mM HEPES, pH 7.9, $420 \mathrm{mM} \mathrm{NaCl}, 15 \mathrm{mM} \mathrm{MgCl} 2$, $0.2 \mathrm{mM}$ EDTA, $25 \%$ (v/v) glycerol, $1 \%(\mathrm{v} / \mathrm{v})$ Nonidet P-40, $0.5 \%$ (v/v) sodium deoxycholic acid, 0.5 mM DTT), incubated for $30 \mathrm{~min}$ at $4{ }^{\circ} \mathrm{C}$, and centrifuged at $5000 \mathrm{~g}$ for $5 \mathrm{~min}$ at $4{ }^{\circ} \mathrm{C}$. The supernatant was collected as the nuclear extract. In order to confirm a successful fractionation, all fractions were routinely tested for the expression of HDAC which should only be present in the nuclear fraction. For whole cell lysate preparation, cells were treated with RIPA lysis buffer (50 mM Tris, pH 7.2, $150 \mathrm{mM} \mathrm{NaCl}, 0.1 \%$ (v/v) SDS, $0.5 \%$ sodium deoxycholic acid, $1 \%(\mathrm{v} / \mathrm{v})$ Triton $\mathrm{X}-100$ ). All buffers were supplemented with protease inhibitors (Sigma) as well as phosphatase inhibitors (Roche). Protein quantification was carried out with the $\mathrm{D}_{\mathrm{C}}$ protein assay (Bio-Rad, Munich, Germany). For co-immunoprecipitations, MCF-7 cells were transiently transfected with plasmids encoding ROR2-Flag [37] and/or Dvl1-myc, Dvl2-myc or Dvl3-myc [38] using Lipofectamine LTX (Thermo Fisher Scientific, Braunschweig, Germany) according to the manufacturer's instructions. Twenty-four hours post transfection, cells were stimulated for 45 min with either control supernatant or supernatant of Wnt5a-overexpressing cells. Wnt-5a conditioned medium was collected from 3T3 murine fibroblasts infected with pMSCV-Xenopus Wnt-5a or an empty control vector. Cells were lyzed in $10 \mathrm{mM}$ HEPES $\mathrm{pH} 7.4,150 \mathrm{mM} \mathrm{NaCl}$, $0.5 \% \mathrm{NP}-40$ and $0.5 \%$ OGP supplemented with protease and phosphatase inhibitors. Up to $750 \mu \mathrm{g}$ protein were used for immunoprecipitation with an anti-Flag antibody (\#8146, cell signaling) and anti-Flag M2 magnetic beads (Sigma) according to standard protocols.

The obtained lysates were subjected to immunoblotting and proteins were detected with antibodies specific to
WNT5a (\#MAB645, R\&D Systems, Wiesbaden, Germany), ROR2, total $\beta$-catenin (\#sc-98486,\#sc-7963, Santa Cruz, Heidelberg, Germany), active $\beta$-catenin, Tubulin (\#05-665,\#05-829, Merck Millipore, Darmstadt, Germany), ROR1, myc, Flag, Dv13, c-Jun or HDAC1 (\#4102,\#2276,\#8146,\#3218,\#9165,\#2062, Cell Signaling, Frankfurt, Germany). All immunoblots were carried out in three technically and biologically independent experiments.

\section{Flow cytometry}

Cell lines were stained with a PE-conjugated monoclonal antibody against human ROR1 (\#357803, BioLegend) according to the manufacturer's instructions. An irrelevant IgG1 antibody was used as respective isotype-matched negative control (BioLegend). Fluorescence was measured with a FACSCanto II flow cytometer (BD Biosciences, Heidelberg, Germany). Flow cytometry results were analyzed using Kaluza, software version 1.2 (Beckman Coulter, Krefeld, Germany).

\section{In-vitro invasion and proliferation assays}

The invasive capacity of the cells was measured in a modified Boyden chamber as previously published [39]. Briefly, $1 \times 10^{5}$ cells were seeded in triplicate on an ECMcoated (R\&D systems, Wiesbaden, Germany) polycarbonate membrane (pore diameter $10 \mu \mathrm{m}$, Nucleopore, Tübingen, Germany) and grown for $96 \mathrm{~h} \mathrm{[39].} \mathrm{Cell} \mathrm{invasion} \mathrm{was}$ quantified by counting the number of invasive cells in the lower wells and relating it to the wildtype control. Viability and real-time proliferation were analyzed using the xCELLigence RTCA DP system (Roche, Mannheim, Germany). For this purpose, $4 \times 10^{4}$ cells were seeded per well in quadruplets and analyzed for $96 \mathrm{~h}$. All invasion and proliferation assays were carried out in three biologically independent experiments.

\section{Immunofluorescence staining}

Cells were stained as previously described using the above mentioned antibodies and were analyzed with either a confocal laser scanning microscope (LSM 510, Zeiss, Göttingen, Germany) (Pukrop et al. [21]) or a conventional fluorescence microscope (DM5000B, Leica Microsystems, Wetzlar, Germany).

\section{Human tissue samples of hepatic metastases and primary tumors}

Formalin-fixed paraffin-embedded (FFPE) hepatic metastases and primary breast cancer samples from patients 
treated at the University Medical Center Göttingen between 1998 and 2011 were obtained from the local Pathology Department. In total, 34 hepatic metastases (either from punch biopsies $(n=27)$ or resection specimens after liver resection $(n=6))$ and 19 matched primary tumors (surgical resection specimens) were available for immunohistochemical analyses (Supplemental Fig. 1B). All patient samples were collected following approval by the local ethics committee (vote: $21 / 3 / 11$ ).

\section{Study cohort}

The patient cohort was characterized in terms of demographics, clinical baseline data, and treatment regimens.

Follow-up examinations were performed according to individual physicians' discretion and data were obtained either from the local clinical cancer registry or the treating physician. OS after primary surgical treatment (OS primary tumor) was defined as the interval between the surgical resection of the primary tumor and cancer-related death. Survival after liver metastasis (OS liver metastasis) was defined as the interval between the surgical resection or biopsy of liver metastasis and death, which was cancerrelated in all cases.

\section{Immunohistochemistry (IHC)}

Immunohistochemical analyses were performed using formalin-fixed, paraffin-embedded (FFPE) tissue samples cut into 2- $\mu \mathrm{m}$-thick slices and stained on a Ventana BenchMark XT immunostainer (Ventana, Tucson, AZ, US) according to standardized protocols.

Estrogen (ER), progesterone (PGR), HER-2 and proliferation index Ki67 were determined (ER and PR were available for all specimens from the routine histopathological work-up) using immunohistochemical staining. For HER-2 staining, a standardized immunohistochemical staining technique was performed using a PATHWAY ${ }^{\circledR}$ anti-HER-2 (4B5) rabbit monoclonal antibody (Ventana Medical Systems, Mannheim, Germany). Heat epitope retrieval using the immunostainer was performed for $60 \mathrm{~min}$ at $100{ }^{\circ} \mathrm{C}$. The anti-HER-2 antibody was incubated at $37{ }^{\circ} \mathrm{C}$ for $32 \mathrm{~min}$. Enzymatic reactivity was visualized by means of horseradish peroxidase with the ultraView Universal DAB Detection Kit (Ventana Medical Systems). HER-2 gene amplification was detected using the Ventana INFORM HER-2 Dual ISH/DNA Probe Cocktail and visualized utilizing two-color chromogenic in situ hybridization (ultraVIEW SISH Detection KIT and ultraVIEW Red ISH DIG Detection Kit, Ventana Medical Systems). The Ki67 antibody used is also a monoclonal mouse antibody (Zytomed Systems, code number MSK018) and was diluted to 1:500.
Purified mouse anti-E-cadherin (BD Biosciences, Heidelberg, Germany) was used after treatment with $\mathrm{CC} 1$ for $60 \mathrm{~min}$ at a dilution of 1:400 for $30 \mathrm{~min}$. The mouse antibody $\beta$ catenin (E-5) sc-7963 (Santa Cruz Biotechnology Inc., Heidelberg, Germany) was used at a dilution of 1:200 for $30 \mathrm{~min}$ to detect $\beta$-catenin. Phospho-c-Jun was visualized by means of the polyclonal Phospho-c-Jun (Ser63) II antibody (Cell Signaling Technology ${ }^{\circledR}$, Massachusetts, USA) at a dilution of 1:50 for $80 \mathrm{~min}$. Heat epitope retrieval was done with $\mathrm{CC} 2$ treatment for $64 \mathrm{~min}$. The OptiView DAB IHC Detection Kit (Ventana Medical Systems, Tucson, Arizona, USA) was used as a secondary antibody for E-cadherin, $\beta$-catenin and Phospho-c-Jun. For the immunohistochemical staining of c-Jun, the monoclonal antibody c-Jun (60A8) Rabbit mAB\#9165 (Cell Signaling Technology ${ }^{\circledR}$, Massachusetts, USA) was used after demasking with CC1 for $60 \mathrm{~min}$. LEF-1 was demasked with $\mathrm{CC} 1$ for $90 \mathrm{~min}$ and stained for $90 \mathrm{~min}$ with the monoclonal antibody Lef1 (C18A7) Rabbit mAb\#2286 (Cell Signaling Technology ${ }^{\circledR}$, Massachusetts, USA) at a dilution of 1:50. The polyclonal antibody Dvl3\#3218 (Cell Signaling Technology ${ }^{\circledR}$, Massachusetts, USA) was used at a dilution of 1:50 for $90 \mathrm{~min}$ after preconditioning with $\mathrm{CC} 1$ for $90 \mathrm{~min}$ for the determination of Dvl3.

\section{Analyses of immunohistochemical stainings and definition of WNT scores}

Tumor cell staining alone was evaluated; microenvironment staining was ignored. For the hormone receptor expression membrane staining activity for ER and PR was determined and rated as positive when $\geq 10 \%$ of tumor cells were positive. Furthermore, the accurate nuclear staining percentage was assessed for Ki67. Owing to the fact that almost all primary and metastases samples were positive for the proliferation index $\mathrm{Ki67}$, the median expression was taken as cutoff to perform survival analyses.

HER-2 expression was scored according to established histopathological guidelines for breast cancer. In the case of equivocal staining, additional slides were prepared for chromogene or silver in situ hybridization (C/S-ISH) [40]. In-situ hybridization was used to reveal gene amplification in specimens scored as IHC2+ and to confirm gene amplification in all IHC3+ cases. Ratios of $>2.2$ indicated HER-2 gene amplification. In the case of an equivocal result for gene amplification (ratio 1.8-2.2), additional cells (at least 20 additional cancer cells) were analyzed. The HER-2 status was defined as positive if tissue samples were scored as $\mathrm{IHC} 2+/ \mathrm{SISH}+$ or $\mathrm{IHC} 3+$ and negative if they were scored as IHC0, IHC1+ or IHC2+/S-ISH-.

For all other stainings forming the WNT scores, antigene immunoreactivity was scored for nuclear staining (Dvl3, Lef1, $\beta$-catenin, Phospho-c-Jun, c-Jun); membrane staining was analyzed for E-cadherin. Staining intensity was assessed 
and the proportion of positive cells was documented when at least 300 tumor cells were accessible. The slides were screened at a low magnification for the pattern and distribution of the staining. The tumor cell percentage was categorized into five groups: $0=0 \% ; 1+=(1-25 \%)$; $2+=(26-50 \%) ; 3+=(51-75 \%) ; 4+=(76-100 \%)$. For the WNT Score nuclear (Dvl3, Lef1, $\beta$-catenin, Phospho-c-Jun, c-Jun) and membrane (E-cadherin) positivity was used based on the percentage of positive tumor cells. Both WNT scores are the sum of the IHC expression of different WNT components and were calculated as follows: $\beta$-catenin-dependent WNT score $=$ staining score $_{\text {nuclear } \beta \text {-catenin }}+$ staining score $_{\text {nuclear Lef1 }}+$ inverse staining score $_{\mathrm{E}-\text { cadherin }}$. Due to the fact, that membrane E-cadherin levels are downregulated during EMT/active $\beta$-catenin-dependent WNT we used for this WNT score the E-cadherin inverse staining score (membrane). We state, that during active $\beta$-catenindependent WNT signaling membrane E-cadherin levels change (e.g. decrease), but the signaling is not independent of E-cadherin.

The $\beta$-catenin-independent WNT score we calculated as follows: $\beta$-catenin-independent $\mathrm{WNT}$ score $=$ staining score $_{\text {nuclear }}$ Dvl3 + staining score $_{\text {nuclear }}$ c-Jun + staining score ${ }_{\text {nuclear }}$ Phopho-c-Jun. All slides were evaluated independently by two different observers, who remained blind to the patient data and clinical outcome. The standardized manner of specimen preparation was performed according to the REMARK guidelines for biomarker studies [41].

\section{Bioinformatics methods and statistical data analysis}

Survival analysis was performed for OS following surgery of the primary tumor (OS primary tumor) as well as following histologically confirmed diagnosis of liver metastasis (OS liver metastasis). Events were defined as cancerrelated death; all other events were considered as censored. Survival data were visualized using Kaplan-Meier plots and significance was calculated using the logrank test for univariate analyses. $p$ values $<0.05$ were considered significant. Pearson's correlation test was used to calculate correlation of expression changes in the breast cancer primaries and matched liver metastases.

All analyses were performed using the free statistical software R (version 2.15.1; http://www.r-project.org).

\section{Results}

\section{ROR1 is overexpressed in basal-like MDA-MB-231 cells}

First we characterized the WNT repertoire of the three model breast cancer cell lines MCF-7, SK-BR-3, and
MDA-MB-231 representing the luminal, ERBB2/HER-2+, and basal-like molecular subtypes of breast cancer. Dvl3, which is known to be essential for WNT signaling in general, was expressed in all three cell lines. While the MDA-MB-231 revealed only moderate expression of $\beta$ catenin, the expression of WNT5a as well as c-Jun was more prominent in the MDA-MB-231 indicating $\beta$-cateninindependent WNT signaling (Fig. 1a, Supplemental Fig. 2A). Moreover, qRT-PCR revealed the $\beta$-catenin-independent WNT receptor ROR1 to be overexpressed in MDA-MB-231, whereas ROR2 was only very weakly expressed in the cell lines and even undetectable in SKBR-3 cells (Fig. 1b). This overexpression of ROR1 in the MDA-MB-231 was confirmed by flow cytometry (Fig. 1c). Considering that the most aggressive, basal-like cell line MDA-MB-231 expressed the highest amounts of $\beta$-catenin-independent WNT proteins while active $\beta$-catenin was found at high levels in the benign, weakly invasive MCF-7 cells as well, these findings further hint towards the importance of the non-canonical signaling cascade for tumor progression.

\section{ROR2 overexpression and ROR1 knockdown}

Previously, we demonstrated overexpression of the homologues receptors ROR 1 and ROR2 in brain metastasis of breast cancer patients [24]. To further investigate the impact of ROR $1 / 2$ overexpression in breast cancer cells, we transfected both the luminal A breast cancer cell line MCF-7 and the ERBB2/HER-2+ cell line SK-BR-3 with a ROR2 construct. Transfection efficiency was verified by immunoblots (Fig. 2a) and ROR2 localization was determined through immunofluorescence staining (Supplemental Fig. 2B). Interestingly, ROR2 overexpression also resulted in an increased expression of ROR1 (Fig. 2a). We then tested the biological behavior of the cell lines. Invasive capacity was greatly increased in the ROR2 overexpressing cells compared to the empty vector control (Fig. 2b) without any changes in cell proliferation (Supplemental Fig. 2C). In the subsequent step, the ROR2 overexpressing MCF-7 and SK-BR-3 cells were characterized with regard to WNT downstream targets using immunoblotting (Fig. 2c). In comparison to the control cells, c-Jun was enriched in the ROR2 overexpressing cells, confirming an activation of $\beta$-catenin-independent WNT signaling. This can be verified by immunofluorescence, which confirms an increase in nuclear c-Jun levels, whereas the $\beta$-catenin staining depicts a cytosolic and membrane localization (Fig. 2d). In contrast, neither an influence on the levels nor the activation of $\beta$-catenin could be detected (Supplemental Fig. 2d). As a proof of concept that $\beta$ catenin-independent WNT signaling via ROR1/2 indeed mediates invasiveness, a ROR1 knockdown was performed 

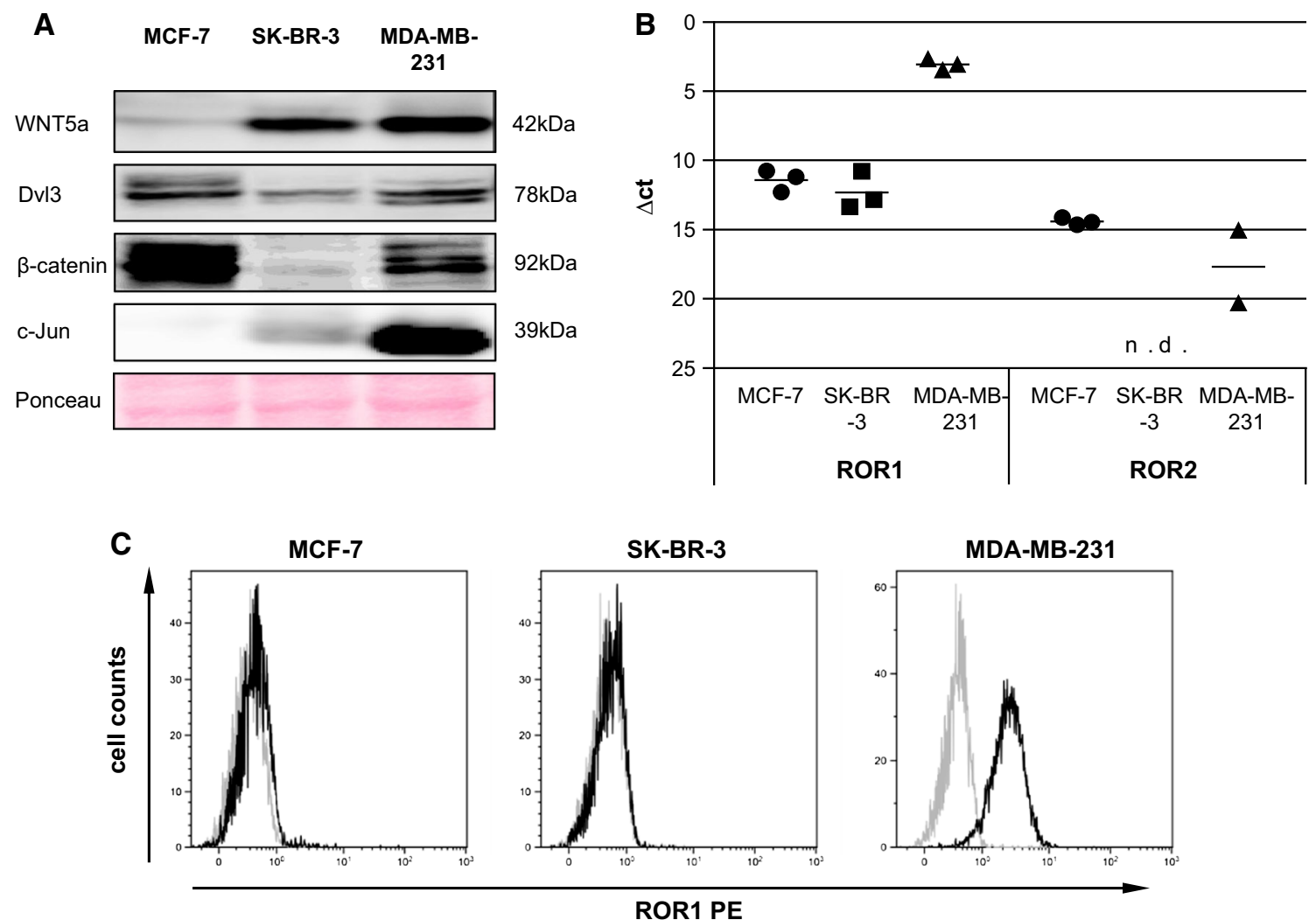

Fig. 1 a Immunoblot for WNT5a, Dvl3, $\beta$-catenin, and c-Jun of MCF-7, SK-BR-3 and MDA-MB-231 cell lysates. B qRT-PCR of MCF-7, SK-BR-3 and MDA-MB-231 for ROR1 and ROR2. Each dot represents one independent biological sample (means, $\mathrm{n}=3$,

in the marked ROR1-expressing cell line MDA-MB-231 and effectiveness validated by immunoblot and flow cytometry (Fig. 2e, Supplemental Fig. 2E). ROR2 protein expression remained undetectable in MDA-MB-231 (Supplemental Fig. 2F). Knockdown of ROR1 significantly decreased the invasive capacity of the cells compared to the control (Fig. 2f), thereby confirming a pro-invasive role for ROR1.

Since it is known that ROR $1 / 2$ signaling, especially after stimulation with Wnt5a, requires Dvl for signal transduction $[42,43]$, we aimed to analyze which of the Dvl proteins (Dvl1, Dv12 or Dvl3) might be a good marker for active ROR signaling in breast cancer. Therefore, we transiently co-transfected MCF-7 cells with Flag-tagged ROR2 and myc-tagged Dvl1, Dvl2 or Dvl3 and performed co-immunoprecipitation after stimulation with Wnt5a. Interestingly, all Dvl proteins were found to interact with ROR2 independent of stimulation with Wnt5a (Supplemental Fig. 2G). Considering that among the Dvl proteins, Dvl3 has already been shown to be highly expressed in cancer patient samples [44-46] and to affect the biological behavior of lung cancer cells mainly through p38 and JNK pathway [47], we decided to include Dvl3, together with n.d. = not detectable). Note that in MDA-MB-231 ROR2 was only detectable in $2 / 3$ samples. C Flow cytometry (gray isotype control, black stained cells for MCF-7, SK-BR-3 and MDA-MB-231) measuring the expression of ROR1

c-Jun, as markers for $\beta$-catenin independent WNT signaling.

\section{Characterization of the patient cohort}

The patient cohort was characterized in terms of demographics, clinical baseline data, and treatment concepts according to the parameters listed in Tables 1 and 2 . In total, 34 hepatic metastases and 19 matched primary tumors were characterized and further classified by IHC (see Materials and methods and Supplemental Fig. 1b).

All patients were diagnosed with breast cancer between 1973 and 2011 at a median age of 57.5 years, $95 \% \mathrm{CI}$ [41.9-76.6]. On diagnosis, patients were staged as follows: UICC I: three patients, UICC II; 19 patients, UICC III: six patients, UICC IV: five patients (one patient was missing UICC data). All patients with metachronic hepatic metastases developed these with a time to $50 \%$ at risk of 87.1 months $95 \%$ CI [52.5-109.2]. Individual treatment strategies are summarized in Supplemental Table 2.

The OS had a time to $50 \%$ at risk of 95.5 months $95 \%$ CI [73.6-127.9]. Survival after diagnosis of liver 

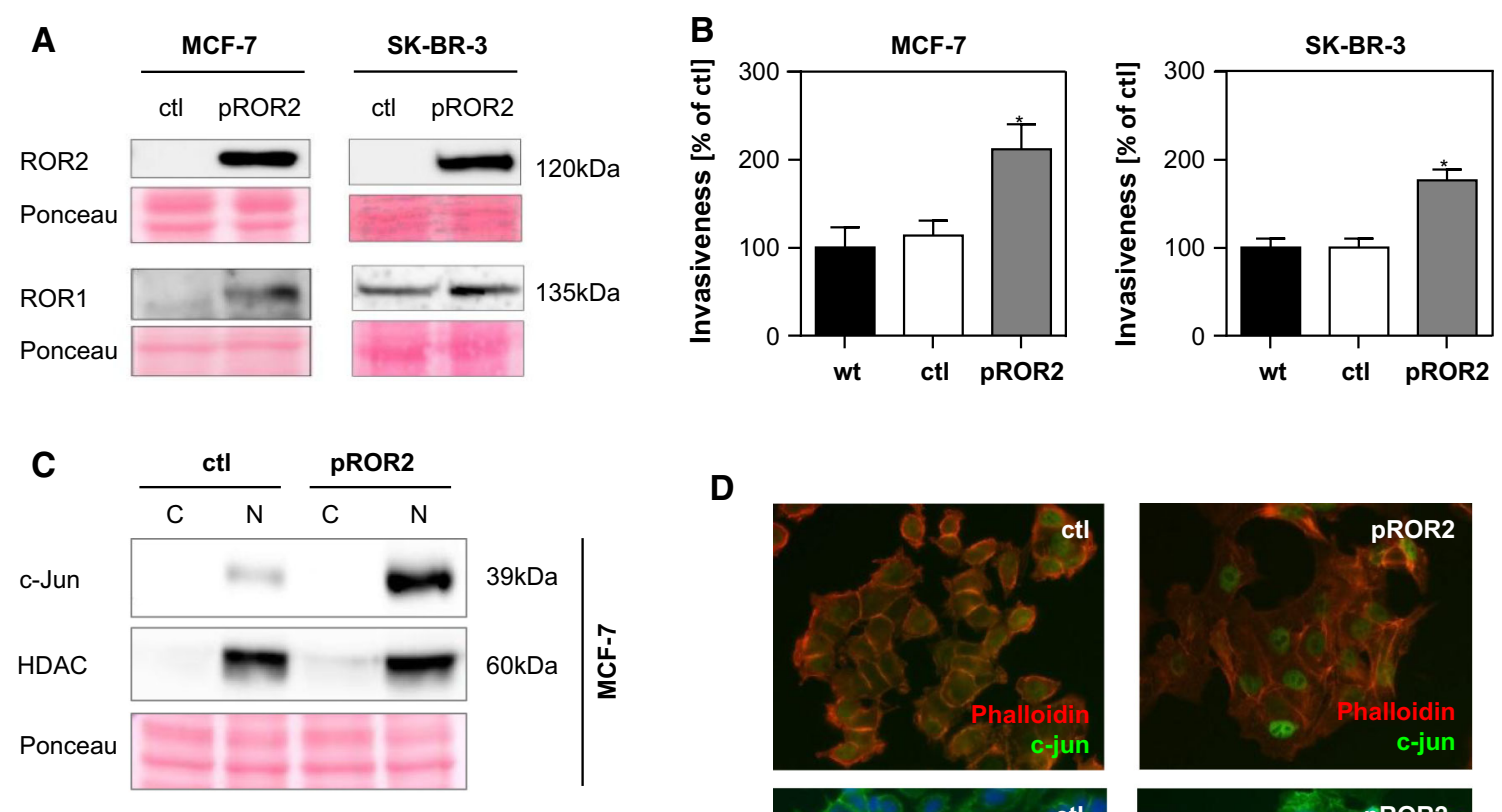

D
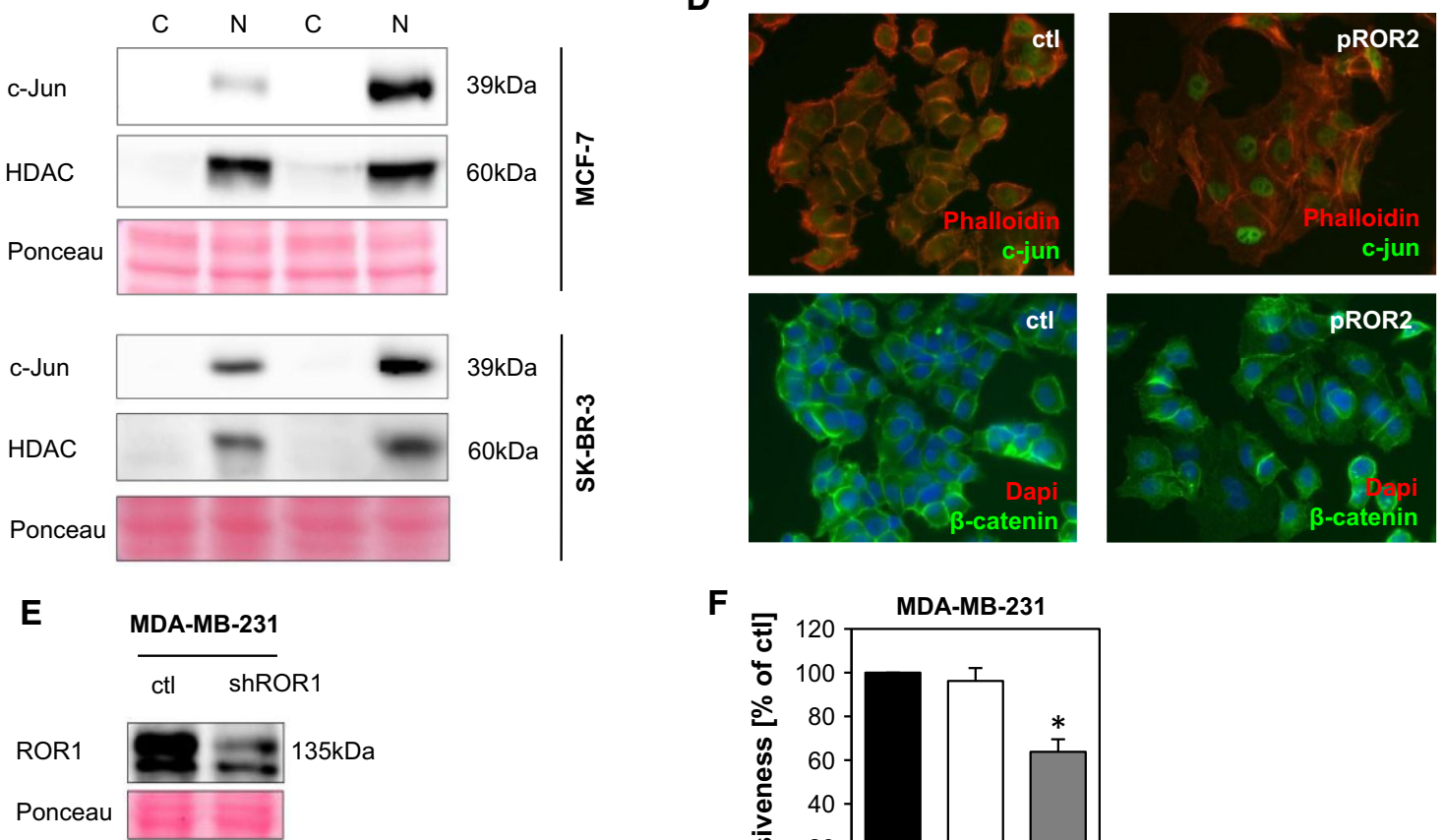

F

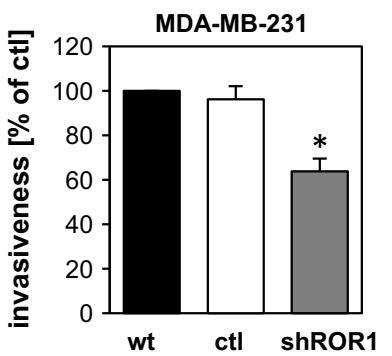

Fig. 2 a Immunoblots showing the expression of ROR1 and ROR2 in MCF-7 and SK-BR-3 cells transfected with either an empty vector (ctl) or a ROR2 overexpression plasmid (pROR2). B In vitro microinvasion assays of ROR2-overexpressing MCF-7 and SK-BR-3 cells compared to wildtype cells (wt) or cells transfected with an empty vector (ctl) (mean $\pm \mathrm{SD}, \mathrm{n}=3, * p<0.001)$. C Immunoblot for c-Jun and HDAC of MCF-7 and SK-BR-3 empty vector (ctl) or ROR2-overexpressing cells for cytoplasmic $(\mathrm{C})$ and nuclear $(\mathrm{N})$ cell

metastasis (OS liver metastasis) revealed a time to $50 \%$ at risk of 15.91 months $95 \%$ CI [9.83-27.06].

The presence of extrahepatic distant metastases on diagnosis lead to a significantly shorter survival (HR $5.3295 \%$ CI [0.85-33.48], $p=0.0481)$. Patients who underwent surgery for resectable liver metastases $(6 / 34,17.6 \%)$ had a significantly improved survival compared to patients without liver surgery (HR $3.3695 \%$ CI [1.14-9.88], $p=0.0207$ ) (Supplemental Fig. 1A). Survival was significantly shorter in older patients at the time of diagnosis of breast cancer (median age 57.5; age >57.6: HR 2.1695\% CI [1.02-4.57], $p=0.0405$ ).

lysates. D Immunofluorescence staining of c-Jun and F-actin (phalloidin) in MCF-7 empty vector (ctl) and ROR2 cells as well as $\beta$ catenin and Dapi in MCF-7 wt and ROR2 cells. E Immunoblot of ROR1 in MDA-MB-231 cells transfected with nonsense control (ctl) or ROR1 (shROR1) shRNA. F In vitro microinvasion assay of MDAMB-231 wildtype (wt), non-sense control (ctl) and ROR1 knockdown (shROR1) cells (mean $\pm \mathrm{SD}, \mathrm{n}=3, * p<0.001$ )

\section{Expression of hormone receptors}

ER and PGR expression were detected in 15/19 (78.95\%) and $13 / 19(68.42 \%)$ of the breast cancer primaries and in $19 / 34(55.88 \%)$ and $11 / 34(32.35 \%)$ of the liver metastases. 4/19 (21.05\%) of the primaries demonstrated HER-2 positivity, whereas in the liver metastases 9/34 (26.47\%) were positive. Focusing on the 19 available pairs of matched primaries and liver metastases, the expression of ER was significantly lower in the metastases (primaries 15/19 (78.95\%); metastases: 11/19 (57.89\%) and significantly 
Table 1 Univariate analysis of clinicopathological baseline data and IHC markers in the breast cancer primaries and their effect on overall survival (OS of the primary breast cancer since first diagnosis)

\begin{tabular}{|c|c|c|c|c|}
\hline Parameter & Classification & Distribution & $\begin{array}{l}\text { Impact on survival } \\
\text { Hazard ratio }[95 \%-\mathrm{CI}]\end{array}$ & $p$ value (logrank) \\
\hline Age & Median $[95 \% \mathrm{CI}]$ & 57.5 [95 \% CI 41.9-76.6] & $\begin{array}{l}\text { Age > 57.6: } \\
2.1695 \% \text { CI [1.02-4.57] }\end{array}$ & $\underline{0.04045}$ \\
\hline Other distant metastases present at diagnosis & $\begin{array}{l}\text { Yes }(\%) \\
\text { No }(\%)\end{array}$ & $\begin{array}{l}21.5 \%(4 / 19) \\
78.95 \%(15 / 19)\end{array}$ & $\begin{array}{l}\text { Present at diagnosis: } \\
5.3295 \% \text { CI [0.85-33.48] }\end{array}$ & 0.04808 \\
\hline Estrogen receptor (ER) & $\begin{array}{l}\text { Positive }(\%) \\
\text { Negative }(\%)\end{array}$ & $\begin{array}{l}78.95 \%(15 / 19) \\
21.5 \%(4 / 19)\end{array}$ & $\begin{array}{l}\text { ER positive: } \\
0.0995 \% \text { CI }[0.01-0.56]\end{array}$ & $\underline{0.001523}$ \\
\hline Progesterone receptor (PGR) & $\begin{array}{l}\text { Positive }(\%) \\
\text { Negative }(\%)\end{array}$ & $\begin{array}{l}68.42 \%(13 / 19) \\
31.58 \%(6 / 19)\end{array}$ & $\begin{array}{l}\text { PGR positive: } \\
0.2195 \% \text { CI [0.05-0.92] }\end{array}$ & 0.02453 \\
\hline Her2/neu & $\begin{array}{l}\text { Positive }(\%) \\
\text { Negative }(\%)\end{array}$ & $\begin{array}{l}21.5 \%(4 / 19) \\
78.95 \%(15 / 19)\end{array}$ & $\begin{array}{l}\text { HER2/new positive: } 0.83 \\
95 \% \text { CI [0.18-3.76] }\end{array}$ & 0.8096 \\
\hline Proliferation index Ki67 & $\begin{array}{l}\text { Positive }(\%) \\
\text { Negative }(\%)\end{array}$ & $\begin{array}{l}89.47(17 / 19) \\
10.53(2 / 19)\end{array}$ & $\begin{array}{l}\text { Ki67 positive: } 1.43 \\
95 \% \text { CI [0.31-6.69] }\end{array}$ & 0.6451 \\
\hline Modified proliferation index Ki67 & $\begin{array}{l}\text { Positive }(\%) \\
\text { Negative }(\%)\end{array}$ & $\begin{array}{l}52.63(10 / 19) \\
47.37 .5(9 / 19)\end{array}$ & $\begin{array}{l}\text { Ki67 > } 20 \% \text { positive: } 3.25 \\
95 \% \text { CI }[1.0-10.5]\end{array}$ & $\underline{0.03831}$ \\
\hline$\beta$-catenin dependent WNT score & $\begin{array}{l}\text { High }>2(\%) \\
\text { Low } \leq 2(\%)\end{array}$ & $\begin{array}{l}42.11(8 / 19) \\
57.89(11 / 19)\end{array}$ & $\begin{array}{l}\text { WNT-Score high: } 0.35 \\
95 \% \text { CI [0.11-1.12] }\end{array}$ & 0.06487 \\
\hline$\beta$-catenin independent WNT score & $\begin{array}{l}\text { High }>4(\%) \\
\text { Low } \leq 4(\%)\end{array}$ & $\begin{array}{l}68.42 \%(13 / 19) \\
31.58 \%(6 / 19)\end{array}$ & $\begin{array}{l}\text { WNT-Score high: } 1.71 \\
95 \% \text { CI [0.63-4.63] }\end{array}$ & 0.2849 \\
\hline
\end{tabular}

Patient cohort was characterized according to listed parameters in the first column. Type of classification and distribution within the cohort as well as impact on survival including $p$ value (logrank) is given for each parameter

Bold and underlined $p$-values are meant to highlight those below 0.05

correlated $(\mathrm{r}=0.51,95 \%$ CI $[0.07-0.78], p=0.02)$. In the matched samples, $13 / 19(68.42 \%)$ of the breast cancer primaries revealed PGR expression, whereas only 6/19 (31/ $0.59 \%)$ liver metastases were positive. Thus, PGR expression also decreased during the development of liver metastasis, however no correlation was detected $(\mathrm{r}=0.16$, $95 \%$ CI [-0.32-0.57], $p=0.52$ ). Within the matched samples, HER-2 expression was $21.05 \%$ in primaries: $4 / 19$ and $26.32 \%$ in metastases: $(5 / 19)$ and significantly correlated $\left(\mathrm{r}=0.86,95 \%\right.$ CI [0.67-095], $\left.p=1.85 \times 10^{-6}\right)$.

Thus, the expression of estrogen and progesterone receptor in the breast cancer primaries is associated with better survival analyzed from the time point of first diagnosis (ER HR: $0.0995 \%$ CI [0.01-0.56], $p=0.0015$ and PGR HR: $0.2195 \%$ CI [0.05-0.92], $p=0.0245$ ) (Fig. 3a and Table 1). In contrast, in the liver metastases the expression of PGR and ER is no longer prognostic analyzed from the time point after liver metastasis resection/ biopsy (Fig. 3a; Table 2).

\section{High proliferation index Ki67 in primary tumors and metastases was associated with shorter survival}

In the primaries, the proliferation index Ki67 ranged from 5 to $80.17 / 19(89.47 \%)$ demonstrated a proliferation index of $\mathrm{Ki} 67 \geq 10 \%$. In $31 / 34(91.18 \%)$ of the liver metastases, a proliferation index of Ki67 [10 \%] was detected with a range from 0 to 80 . Owing to the fact that almost all primary and metastases samples were positive for the proliferation index Ki67, the median expression was taken as cutoff to perform survival analyses. Taking the primaries' median proliferation index Ki67 of $20 \%$, a higher proliferation index Ki67 was associated with shorter survival (HR $3.2595 \%$ CI [1.0-10.5], $p=0.0383$ ). The same is true for the liver metastases (median $30 \%$ ), for which survival was significantly shorter when Ki67 staining was above the median (HR 2.46, $95 \%$ CI [1.11-5.44], $p=0.0222$ ) (Fig. 3b).

\section{Expression of WNT markers in primaries and metastases}

E-cadherin expression was detected in all 19/19 (100\%) of the breast cancer primaries. Three samples were graded as $1+$, one sample as $2+$ and fifteen samples as 4+ (Fig. $4 \mathrm{a}+\mathrm{b}$ ). In the liver metastases, 30/34 (88.23\%) of the samples stained positive for E-cadherin. Apart from two samples graded as $1+$ and $3+$ respectively, all other 28 samples were graded as $4+$. Nuclear detection of $\beta$-catenin was neither possible in the primaries $(0 \%)$ nor in the liver metastases $(0 \%)$ (Fig. $4 \mathrm{e}+\mathrm{f}$ ). Nuclear c-Jun was detected in $18 / 19(94.73 \%)$ of the breast cancer primaries. Three 
Table 2 Univariate analysis of clinicopathological baseline data and IHC markers derived from breast cancer liver metastases and their effect on overall survival (OS after occurrence of liver metastasis)

\begin{tabular}{|c|c|c|c|c|}
\hline Parameter & Classification & Distribution & $\begin{array}{l}\text { Impact on survival } \\
\text { Hazard ratio }[95 \% \mathrm{CI}]\end{array}$ & $p$ value (logrank) \\
\hline \multirow[t]{2}{*}{ Type of surgery } & Resection (\%) & $20.58 \%(7 / 34)$ & Punch: 3.36 & $\underline{0.0207}$ \\
\hline & Punch $(\%)$ & $79.41 \%(27 / 34)$ & $95 \%$ CI [1.14-9.88] & \\
\hline \multirow{2}{*}{$\begin{array}{l}\text { Other distant metastases present at } \\
\text { liver metastasis }\end{array}$} & Yes $(\%)$ & $44.12 \%(15 / 34)$ & Present at diagnosis: 1.70 & 0.1662 \\
\hline & No $(\%)$ & $55.88 \%(19 / 34)$ & $95 \%$ CI $[0.80-3.65]$ & \\
\hline \multirow{2}{*}{$\begin{array}{l}\text { Chemotherapy (CTx) after } \\
\text { diagnosis of liver metastasis }\end{array}$} & Yes $(\%)$ & $86.21 \%(25 / 29 *)$ & Yes: 2.21 & 0.1911 \\
\hline & No $(\%)$ & $13.79 \%(19 / 29 *)$ & $95 \%$ CI $[0.65-7.50]$ & \\
\hline \multirow[t]{2}{*}{ Estrogen receptor (ER) } & Positive $(\%)$ & $55.88 \%(19 / 34)$ & ER positive: 0.87 & 0.7003 \\
\hline & Negative (\%) & $44.12 \%(15 / 34)$ & $95 \%$ CI $[0.42-1.80]$ & \\
\hline \multirow[t]{2}{*}{ Progesterone receptor (PGR) } & Positive $(\%)$ & $32.35 \%(11 / 34)$ & PR positive: 0.93 & 0.8428 \\
\hline & Negative (\%) & $67.65 \%(23 / 34)$ & $95 \%$ CI [0.43-1.99] & \\
\hline \multirow[t]{2}{*}{ Her2/neu } & Positive (\%) & $26.47 \%(9 / 34)$ & HER2/neu positiv: 1.06 & 0.8997 \\
\hline & Negative $(\%)$ & $73.53 \%(25 / 34)$ & $95 \%$ CI $[0.45-2.50]$ & \\
\hline \multirow[t]{2}{*}{ Proliferation index Ki67 } & Positive (\%) & $91.18 \%(31 / 34)$ & Ki67 positive: 2.79 & 0.1481 \\
\hline & Negative $(\%)$ & $8.82 \%(3 / 34)$ & $95 \%$ CI [0.65-11.92] & \\
\hline \multirow[t]{2}{*}{ Modified proliferation index Ki67 } & Positive (\%) & $52.94 \%(18 / 34)$ & Ki67 $>30 \%$ positive: 2.46 & $\underline{0.0222}$ \\
\hline & Negative $(\%)$ & $47.06 \%(16 / 34)$ & $95 \%$ CI [1.11-5.44] & \\
\hline \multirow[t]{2}{*}{$\beta$-catenin dependent WNT score } & High $>1(\%)$ & $44.12 \%(15 / 34)$ & Wnt-Score high: 0.74 & 0.4179 \\
\hline & Low $\leq 1(\%)$ & $55.88 \%(19 / 34)$ & $95 \%$ CI [0.35-1.55] & \\
\hline$\beta$-catenin independent & High $>5(\%)$ & $64.71 \%(22 / 34)$ & Wnt-Score high: 2.19 & $\underline{0.0391}$ \\
\hline WNT score & Low $\leq 5(\%)$ & $35.29 \%(12 / 34)$ & $95 \%$ CI [1.02-4.69] & \\
\hline
\end{tabular}

Patient cohort was characterized according to listed parameters in the first column. Type of classification and distribution within the cohort as well as impact on survival including $p$ value (logrank) is given for each parameter

Bold and underlined $p$-values are meant to highlight those below 0.05

* Cases where not for all patients baseline data was available

samples were graded as $1+$, eight as $2+$, five as $3+$ and two as $4+$. All the liver samples (34/34) expressed nuclear c-Jun. Five samples were graded as $1+$, ten as $2+$, thirteen as $3+$ and six as $4+$ (Fig. $4 \mathrm{i}+\mathrm{j}$ ). Nuclear Phospho-c-Jun was expressed in $18 / 19(94.73 \%)$ of the primary breast cancer samples. Fifteen samples were graded as $1+$, and two samples with $2+$ and $3+$, respectively.

In the liver metastases, 32/34 $(94.11 \%)$ expressed nuclear Phospho-c-Jun. Twenty-one samples were graded as $1+$, eight as $2+$, and two samples as $3+$ and $4+$, respectively (Fig. $4 \mathrm{~g}+\mathrm{h}$ ).

Nuclear Lef1 expression was detected in 18/19 $(94.73 \%)$ of the primary samples (Fig. $4 \mathrm{c}+$ d). Four samples were graded as $4+$, nine as $2+$, three as $3+$ and two as $4+$. In the liver metastases, nuclear Lef1 expression was detected in $29 / 34(85.29 \%)$ of the samples. Sixteen samples were graded as $1+$, eight as $2+$, three as $3+$ and two as 4+. Nuclear Dvl3 was detected in 15/19 (78.94\%) of the primaries. Nine samples were graded as $1+$, five as $2+$ and one as 3+. In the liver metastases, 33/34 (97.05\%) were positive for nuclear Dvl3. Twenty-four were graded as $1+$, six as $2+$, two as $3+$ and one as $4+$ (Fig. $4 \mathrm{k}+1$ ).

\section{WNT score was associated with shorter survival}

The median $\beta$-catenin-dependent WNT score (representing $\beta$-catenin-dependent WNT signaling) was two (95\% CI [0.45-6.1]) in the primary tumors and one $(95 \% \mathrm{CI}$ $[0.0-7.0])$ in the liver metastases. The median $\beta$-cateninindependent WNT score was four (95\% CI [1.45-8.1]) in the primaries and five (95\% CI [2.7-9.2]) in the liver metastases (Supplemental Fig. 3). In the matched liver metastases samples, the $\beta$-catenin-dependent WNT score decreased to one (95\% CI [0.0-7.0]) and the $\beta$-cateninindependent WNT score increased to 5 (95\% CI [1.9-9.1]). In the breast cancer primaries, neither the $\beta$ catenin-dependent WNT score (HR $0.35 \quad 95 \%$ CI [0.11-1.12], $p=0.0649)$ nor the $\beta$-catenin-independent WNT score alone (HR $1.71 \quad 95 \%$ CI [0.63-4.63], $p=0.2849$ ) were of prognostic value. In contrast, in the liver metastases, a high $\beta$-catenin-independent WNT score (HR $2.1995 \%$ CI [1.02-4.69], $p=0.0391$ ) proved to be unfavorable analyzed from the time point after liver metastasis, whereas the $\beta$-catenin-dependent WNT score was not prognostic (HR $0.74 \quad 95 \%$ CI [0.35-1.55], 
Fig. 3 Kaplan-Meier curves illustrate that ER expression in the primary tumor but not in the liver metastases is correlated with a good prognosis (a). Positivity for the proliferation index Ki67 in the primary tumor tissue as well as in the liver metastases (b) is associated with reduced overall survival

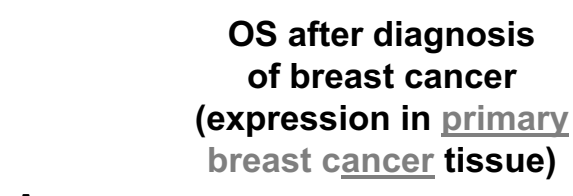

A

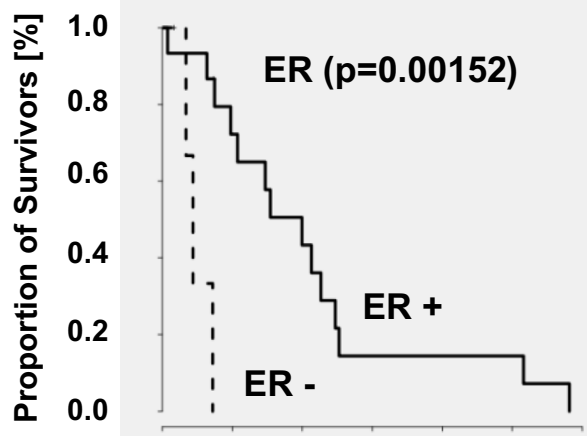

B

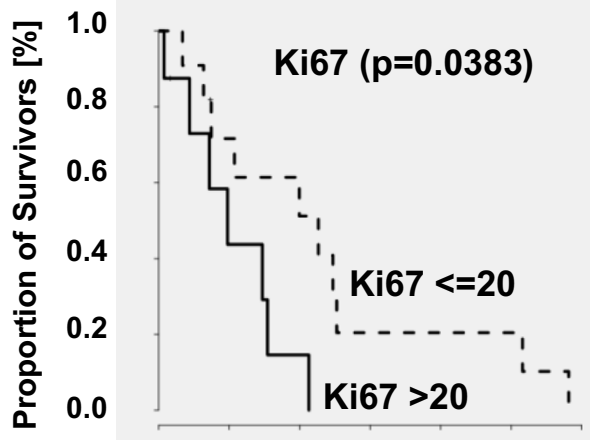

OS after resection of liver metastasis (expression in metastatic liver tissue)
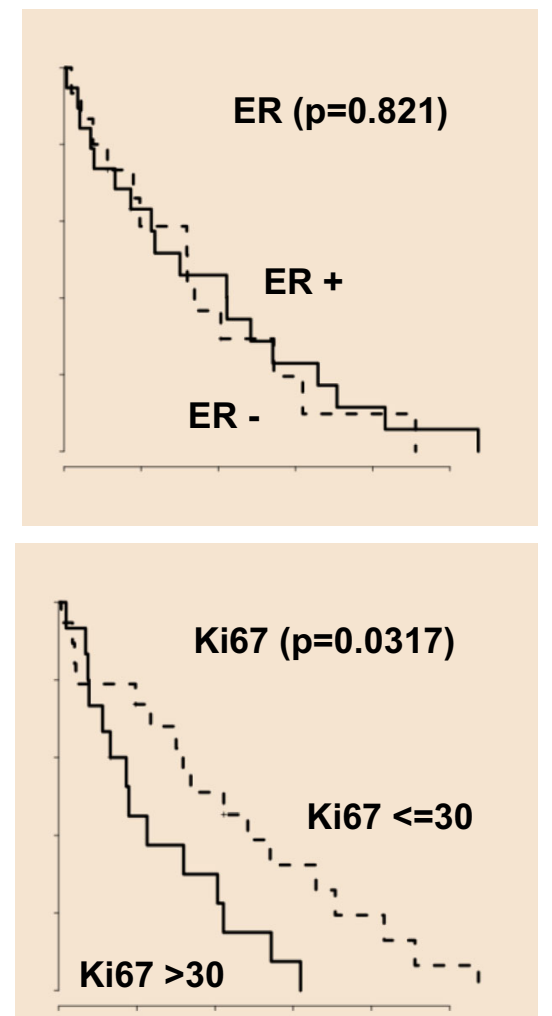

$p=0.4179)$ (Fig. $5 \mathrm{a}+$ b). Taken together, the IHC results revealed a significance of $\beta$-catenin-independent WNT signaling during liver metastasis which is correlated with an unfavorable prognosis at the time point of resection/ biopsy of the liver metastasis. In contrast, a high $\beta$-catenindependent WNT score has a tendency for better OS in the primary, while at the time point of liver metastasis the score is not correlated with prognosis any more.

\section{Discussion}

The liver is the second most frequent site of metastasis in breast cancer patients. Furthermore, liver metastases remain associated with an unfavorable prognosis and there is an urgent need to improve the therapeutic options. Along this line, both this and previous studies indicate the potential benefit of resecting solitary breast cancer liver metastases as already established for patients with metastatic colorectal cancer [3, 47-49]. However, all reports available are retrospective and included small patient cohorts; randomized or even prospective trials are still missing. In a multimodal tailored approach, it is crucial to identify patient subgroups that benefit from specific treatment options including surgical resection, based on distinct biomarker profiles or prognostic parameters.

In the current study, we investigated both well-established and innovative biomarkers in synchronous $(n=5)$ or metachronous $(n=29)$ liver metastases of breast cancer patients as well as in available matched primary tumors $(\mathrm{n}=19)$. While biomarker analysis identified the proliferation index Ki67 to be prognostic in both types of tissue (primary and metastatic), ER status was shown to lose its prognostic value: Surprisingly, ER positivity in the metastatic samples was not prognostic anymore analyzed from the time point of liver metastasis, although it was prognostic in the matched primary tumors analyzed from the time point of the first diagnosis of the primary as expected. This discrepancy may be attributed to the fact that metastatic breast cancer cells are more resistant to anti-hormonal treatment than non-metastatic cells [50]. Furthermore, the unique microenvironment of the metastatic liver tissue could be a second decisive parameter [51]. Previously, significant differences in treatment 

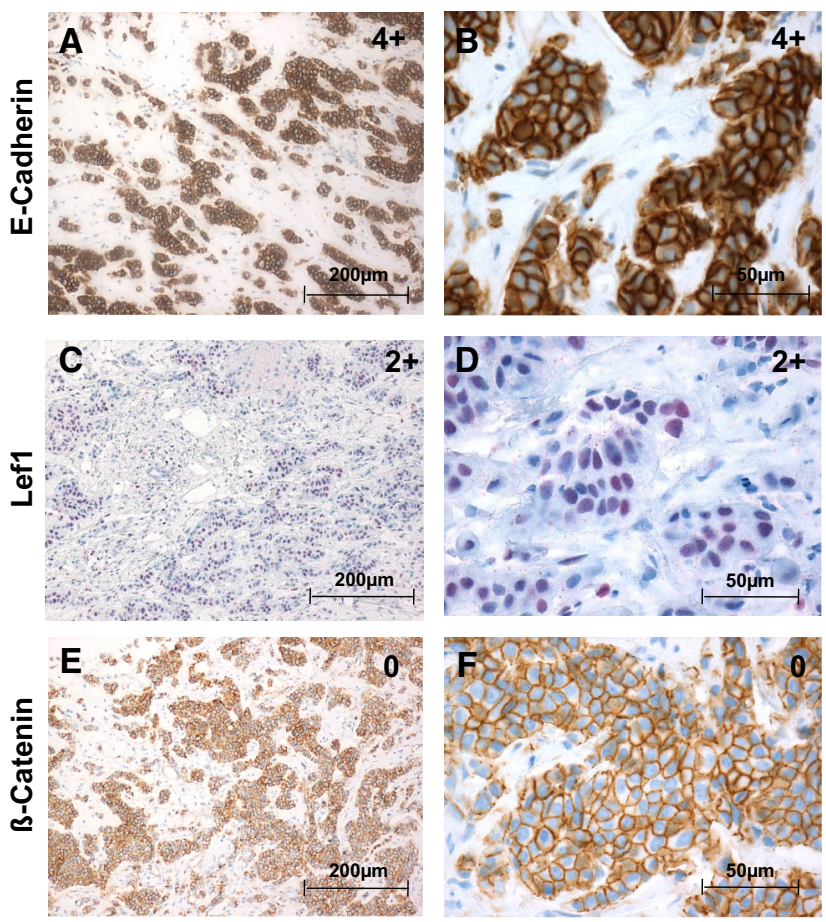

Fig. 4 Immunohistochemical stainings for all proteins analysed were performed on primary tumors and metastases respectively. Representative pictures are shown for stainings of primary tumor samples (a-f) and on metastatic tissue (g-l). IHC-staining of membrane E-cadherin showing a positivity in primary tumor cells of $>75 \%$ in $20 \times$ (a) and $40 \times$ magnification (b); nuclear Lef1 positivity is shown at $20 \times$ (c) and $40 \times$ magnification of primary tumor tissue being positive in $30 \%$ of tumor cells (d); $\beta$-catenin staining is shown in panel $\mathbf{e}(20 \times)$ and $\mathbf{f}$ without any nuclear activity. Representative examples of nuclear Phospho-c-Jun staining is shown in $\mathbf{g}(20 \times)$ and h $(40 \times)$ with a positivity rate of $>26 \%$ for intrahepatic breast cancer

response in a mouse model could be observed, dependent on the anatomical injection sites. While various subcutaneously injected cancer cells responded very well to immune therapy, the response was less pronounced in the orthotopic models [52]. However, no studies have been undertaken comparing the treatment response of estrogenreceptor-positive breast cancer cells injected at various anatomical sites (breast versus liver or lung) and treated subsequently with Tamoxifen or other anti-hormonal drugs.

Additionally, current investigations detected a genomic evolution with gain of, tissue-specific and de novo mutations in the metastatic samples in comparison to the primary tumor [53-56]. This subsequently leads to phenotypic changes of the malignant cells as well as changes in the activity of directly and indirectly affected pathways. Recently, a significant overexpression of HER-3 was described for brain metastasis. Interestingly, the ligand NRG1/2 was barely expressed in the metastatic cells, thus the ligand seems to derive from the brain
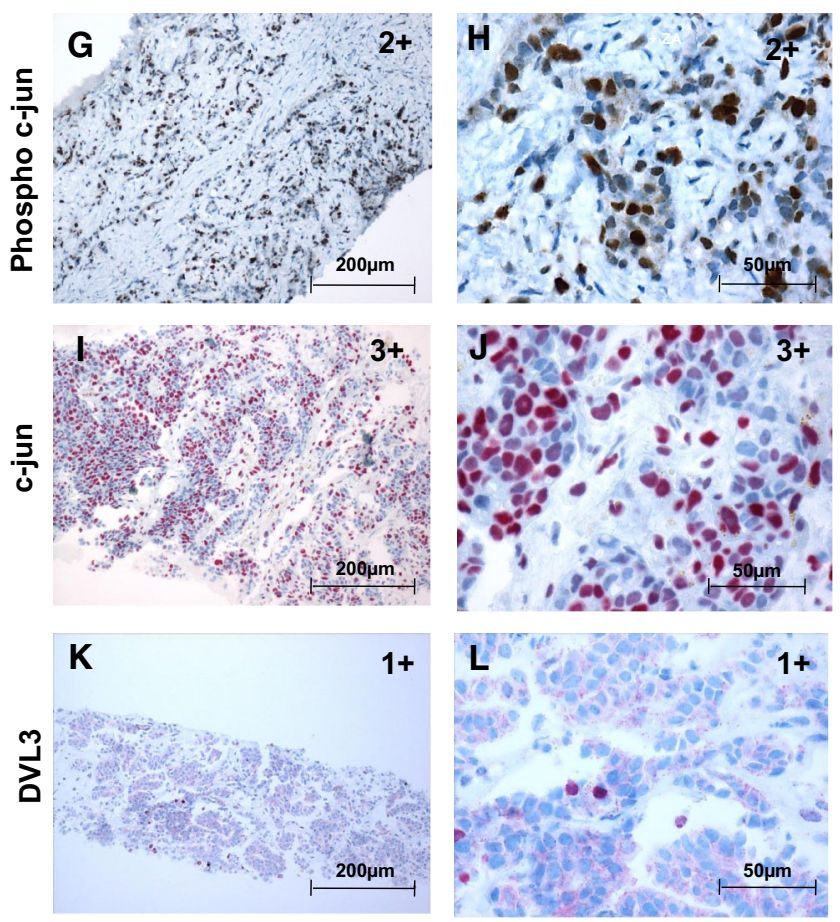

metastases cells; nuclear c-Jun staining is represented in panels $\mathbf{i}(20 \times)$ and $\mathbf{j}(40 \times)$ showing positive stained nuclei in $>76 \%$ of metastatic tissue; nuclear Dvl3 staining is also represented in liver metastases beeing positive in $<25 \%$ of metastases cells at a magnification of $20 \times(\mathbf{k})$ and $40 \times(\mathbf{l})$. For all markers, the specific expression pattern was analyzed for primaries and metastases and classified into five groups: $0=0 \%, 1+=1-25 \%, 2+=26-50 \%$, $3+=51-75 \%$ and $4+=76-100 \%$ of the tumor cells with positive ( $\geq 1)$ staining. Bar: $200 \mu \mathrm{m}(\mathbf{a}, \mathbf{c}, \mathbf{e}, \mathbf{g}, \mathbf{i}$ and $\mathbf{k})$ and $50 \mu \mathrm{m}(\mathbf{b}, \mathbf{d}, \mathbf{f}, \mathbf{h}$, $\mathbf{j}$ and $\mathbf{l})$

microenvironment [57]. This again indicates a very important influence of the microenvironment of the affected organ.

Nonetheless, both (genetic) adaptation of the tumor cells to the metastatic host organ during the process of metastasis and the influence of the new microenvironment are very obvious explanations for our finding that ER expression as a biomarker changes its prognostic capacity in the metastatic tissue.

In this line, the $\beta$-catenin-independent WNT score gains prognostic impact in the metastatic tissue of the liver, which further implies the above described mechanisms, in particular the adaptation during the process of metastasis and to the new host microenvironment. Both processes presuppose an enormous plasticity of the metastatic cells with subsequent differential gene/protein expression at the different metastatic steps and sites of metastases. While during progression in the primary tumor, pre-metastatic cells have to gain mesenchymal characteristics (EMT), they have to regain epithelial features (MET) and 
Fig. 5 No prognostic impact could be shown for the $\beta$ catenin-dependent WNT score (a). In contrast, the $\beta$-cateninindependent WNT score has prognostic impact on survival in the metastatic setting (b).

Survival rates are depicted with Kaplan-Meier-curves in months

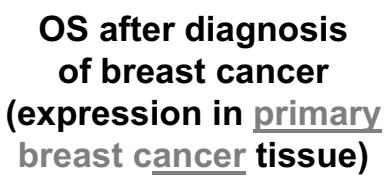

A

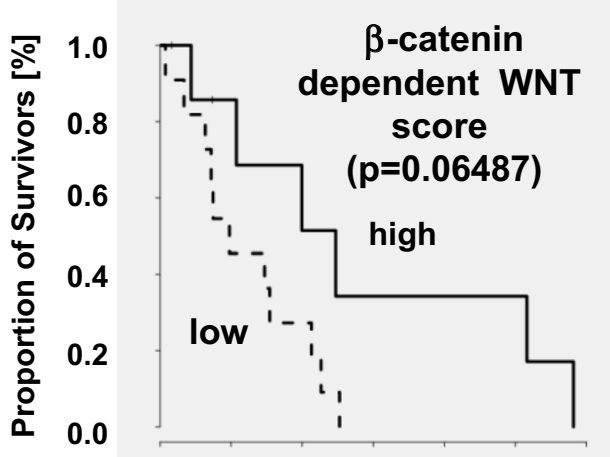

B

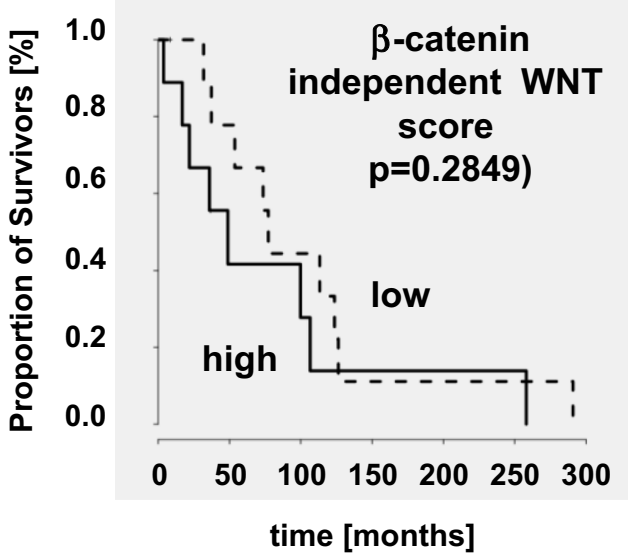

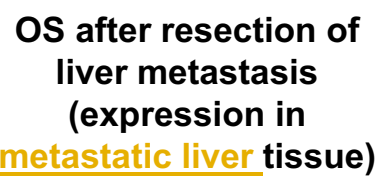
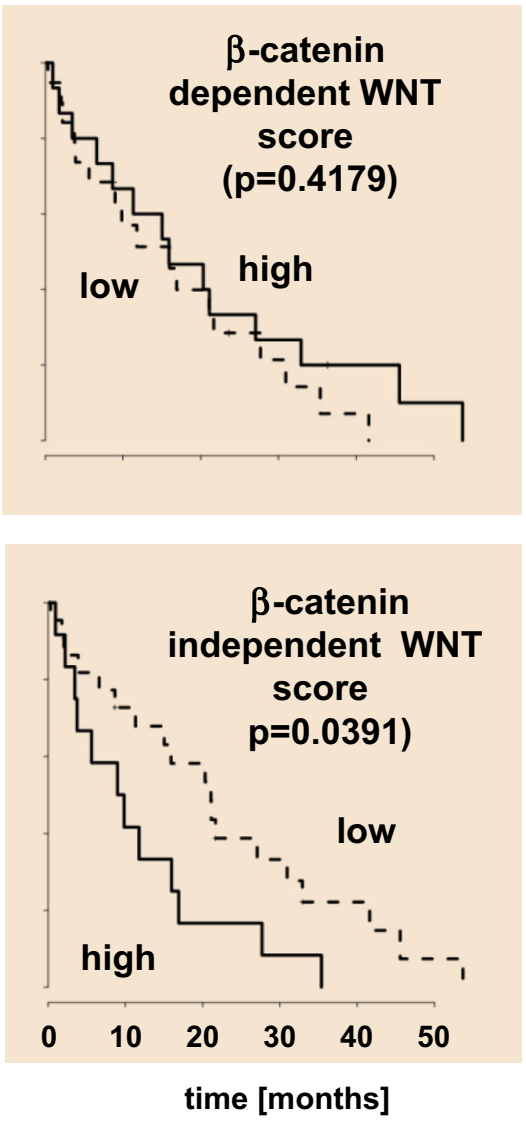

polarization of the pre-metastatic cells in the newly nascent metastatic tissue at the distant sites. The latter process is well described during embryonic development for the establishment of the mesoderm. In that case, mesenchymal cells also regain epithelial characteristics (MET) in a mesenchymal neighborhood that is WNT/ PCP-signaling-dependent. Furthermore, WNT/PCP-signaling regulates not only the establishment but also the maintenance of the epithelial polarity and orientation of a single cell in the overall context of the tissue. Recent findings of $\beta$-catenin-independent WNT components in cancer also strengthen their role during metastasis. For example, in breast cancer, the WNT/PCP pathway was essential in the tumor-stroma communication via exosomes to gain metastatic features [58]. We demonstrated that macrophage- and microglia-derived WNT-signaling enhanced breast cancer invasion in a $\beta$-catenin-independent way [18, 21, 59]. The latter interaction additionally supported the colonization of the brain tissue $[18,21]$ and we described overexpression of c-Jun and ROR1/ROR2 in metastatic brain tissue of breast cancer patients while detecting no nuclear $\beta$-catenin [23]. This is in line with our in vitro findings that, while total and active $\beta$-catenin were detectable in the benign MCF-7 cell line and the invasive, basal-like breast cancer cell line MDA-MB-231, the expression of $\beta$-catenin-independent WNT ligands seemed to increase invasive- and aggressiveness $(\mathrm{MCF}-7<\mathrm{SK}$ BR3 < MDA-MB-231). All these findings underline the role of $\beta$-catenin-independent signaling in the later stages of metastasis. Moreover, there is an increase of the WNT- $\beta$ catenin-independent score from the primary to the liver metastasis. Current genomic investigations also detected an evolution with gain of tissue-specific and de novo genetic mutations in the metastatic samples in comparison to the primary tumor [53-55, 60, 61]. This subsequently leads to phenotypic changes of the malignant cells as well as changes in the activity of directly and indirectly affected pathways. Recently, it was furthermore described for brain metastasis a significant activation of HER-3. Interestingly, the ligand NRG1/2 was barely expressed in the metastatic cells, thus the ligand seems to derive from the brain microenvironment [57]. 
All these findings underline the role of $\beta$-catenin-independent signaling in the later stages of metastasis. However, so far this has received little attention compared to $\mathrm{WNT} / \beta$-catenin signaling.

However, further studies are required for a more specific characterization of the role of the microenvironment in the development of liver metastases and liver-specific mutations or pathway activations. Here we clearly demonstrate a role of the WNT/ $\beta$-catenin-independent signaling pathway during this process.

Taken together, the presented data clearly demonstrate that biomarkers derived from studies in primary tumors cannot simply be translated to the metastatic tissue because of the parallel evolution of the metastatic cells and the organ-specific growth conditions accountable by their specific microenvironments. Furthermore, we revealed the significance of $\beta$-catenin-independent WNT signaling at least for liver metastasis. However, so far the WNT/ $\beta$ catenin independent signaling has received little attention compared to $\mathrm{WNT} / \beta$-catenin signaling. In conclusion, we suggest that prognostic biomarkers should be implemented in the clinical decision making or stratification of patients with liver metastasis of breast cancer in multimodal treatment strategies. This may include the resection of breast cancer liver metastases in selected patients.

Acknowledgments The authors would like to thank Lena Ries, Meike Schaffrinski and Matthias Schulz for their excellent technical assistance and Birgit Jünemann for providing tissue slides and for performing immunohistochemical staining and in situ hybridization. Robert Slany helped generating a WNT-5a and an empty control vector. The authors express their gratitude to Andrew Entwistle and Darren Oram for their copy-editing of the manuscript. This work was supported by the German Research Foundation (DFG) clinical research unit 179, by the German Ministry of Education and Research (BMBF) project MetastaSys (0316173) and Research Program of the Faculty of Medicine, Georg-August-University Göttingen, Germany.

Open Access This article is distributed under the terms of the Creative Commons Attribution 4.0 International License (http://creative commons.org/licenses/by/4.0/), which permits unrestricted use, distribution, and reproduction in any medium, provided you give appropriate credit to the original author(s) and the source, provide a link to the Creative Commons license, and indicate if changes were made.

\section{References}

1. De Angelis R et al (2014) Cancer survival in Europe 1999-2007 by country and age: results of EUROCARE-5-a population-based study. Lancet Oncol 15(1):23-34

2. Cardoso F et al. (2014) ESO-ESMO 2nd international consensus guidelines for advanced breast cancer $(\mathrm{ABC} 2)$ dagger. Annals of oncology: Official Journal of the European Society for Medical Oncology/ESMO vol 25(10), pp 1871-88

3. Ruiterkamp J, Ernst MF (2011) The role of surgery in metastatic breast cancer. Eur J Cancer 47(Suppl 3):S6-S22
4. Choti MA (2014) Liver-directed treatments for metastatic colorectal cancer. Curr Treat Options Oncol 15(3):456-464

5. Elsberger B, Roxburgh CS, Horgan PG (2014) Is there a role for surgical resections of hepatic breast cancer metastases? Hepatogastroenterology 61(129):181-186

6. Page AJ et al (2014) Advances in understanding of colorectal liver metastasis and implications for the clinic. Expert Rev Gastroenterol Hepatol 9(2):245-259

7. Krop IE et al (2012) A phase II study of trastuzumab emtansine in patients with human epidermal growth factor receptor 2-positive metastatic breast cancer who were previously treated with trastuzumab, lapatinib, an anthracycline, a taxane, and capecitabine. J Clin Oncol 30(26):3234-3241

8. Emons G, Ghadimi M, Grade M (2015) General principles of tumour biology in visceral surgery. Zentralbl Chir 140(1):74-82

9. Nguyen DX, Bos PD, Massague J (2009) Metastasis: from dissemination to organ-specific colonization. Nat Rev Cancer 9(4):274-284

10. Vanharanta S, Massague J (2013) Origins of metastatic traits. Cancer Cell 24(4):410-421

11. Nguyen DX, Massague J (2007) Genetic determinants of cancer metastasis. Nat Rev Genet 8(5):341-352

12. Langley RR, Fidler IJ (2011) The seed and soil hypothesis revisited - the role of tumor-stroma interactions in metastasis to different organs. Int J Cancer (J Int Cancer), vol 128(11), pp 2527-2535

13. Gerlinger $M$ et al (2012) Intratumor heterogeneity and branched evolution revealed by multiregion sequencing. $\mathrm{N}$ Engl $\mathrm{J}$ Med 366(10):883-892

14. Huang Y et al (2014) Multilayered molecular profiling supported the monoclonal origin of metastatic renal cell carcinoma. Int $\mathrm{J}$ Cancer (J Int Cancer), vol 135(1), pp 78-87

15. Klein CA (2009) Parallel progression of primary tumours and metastases. Nat Rev Cancer 9(4):302-312

16. Stoecklein NH, Klein CA (2010) Genetic disparity between primary tumours, disseminated tumour cells, and manifest metastasis. Int J Cancer (J Int Cancer), vol 126(3), pp 589-98

17. Chambers AF, Groom AC, Macdonald IC (2002) Dissemination and growth of cancer cells in metastatic sites. Nat Rev Cancer 2(8):563-572

18. Chuang $\mathrm{HN}$ et al (2013) Carcinoma cells misuse the host tissue damage response to invade the brain. Glia 61(8):1331-1346

19. Kienast $Y$ et al (2009) Real-time imaging reveals the single steps of brain metastasis formation. Nat Med 16(1):116-122

20. Valiente $M$ et al (2014) Serpins promote cancer cell survival and vascular co-option in brain metastasis. Cell 156(5):1002-1016

21. Pukrop T et al (2010) Microglia promote colonization of brain tissue by breast cancer cells in a Wnt-dependent way. Glia 58(12):1477-1489

22. Bleckmann A et al (2013) Nuclear LEF1/TCF4 correlate with poor prognosis but not with nuclear beta-catenin in cerebral metastasis of lung adenocarcinomas. Clin Exp Metastasis 30(4):471-482

23. Klemm $F$ et al (2011) beta-catenin-independent WNT signaling in basal-like breast cancer and brain metastasis. Carcinogenesis 32(3):434-442

24. Clevers H, Loh KM, Nusse R (2014) Stem cell signaling. An integral program for tissue renewal and regeneration: wnt signaling and stem cell control. Science 346(6205): 1248012

25. Nusse R (2012) Wnt signaling. Cold Spring Harb Perspect Biol 4(5):a011163

26. Reya T, Clevers H (2005) Wnt signalling in stem cells and cancer. Nature 434(7035):843-850

27. Gessert S, Kuhl M (2010) The multiple phases and faces of wnt signaling during cardiac differentiation and development. Circ Res 107(2):186-199 
28. Ocana $\mathrm{OH}$ et al (2012) Metastatic colonization requires the repression of the epithelial-mesenchymal transition inducer Prrx1. Cancer Cell 22(6):709-724

29. Giancotti FG (2013) Mechanisms governing metastatic dormancy and reactivation. Cell 155(4):750-764

30. Li J, Zhou BP (2011) Activation of beta-catenin and Akt pathways by Twist are critical for the maintenance of EMT associated cancer stem cell-like characters. BMC Cancer 11:49

31. van de Wetering M et al (2001) Mutant E-cadherin breast cancer cells do not display constitutive Wnt signaling. Cancer Res 61(1):278-284

32. Gilles $\mathrm{C}$ et al (2003) Transactivation of vimentin by beta-catenin in human breast cancer cells. Cancer Res 63(10):2658-2664

33. Zhang $S$ et al (2012) ROR1 is expressed in human breast cancer and associated with enhanced tumor-cell growth. PLoS ONE 7(3): 31127

34. Henry C et al (2015) Expression of the novel Wnt receptor ROR2 is increased in breast cancer and may regulate both beta-catenin dependent and independent Wnt signalling. J Cancer Res Clin Oncol 141(2):243-254

35. Kikuchi A et al (2012) Wnt5a: its signalling, functions and implication in diseases. Acta Physiol 204(1):17-33

36. Pukrop T, Binder C (2008) The complex pathways of Wnt 5a in cancer progression. J Mol Med 86(3):259-266

37. Witte F et al (2010) Receptor tyrosine kinase-like orphan receptor 2 (ROR2) and Indian hedgehog regulate digit outgrowth mediated by the phalanx-forming region. Proc Natl Acad Sci USA 107(32):14211-14216

38. Gentzel M et al (2015) Distinct functionality of dishevelled isoforms on $\mathrm{Ca} 2+/$ calmodulin-dependent protein kinase 2 (CamKII) in Xenopus gastrulation. Mol Biol Cell 26(5): 966-977

39. Hagemann $\mathrm{T}$ et al (2004) Enhanced invasiveness of breast cancer cell lines upon co-cultivation with macrophages is due to TNFalpha dependent up-regulation of matrix metalloproteases. Carcinogenesis 25(8): 1543-1549

40. van de Vijver M et al (2007) Chromogenic in situ hybridisation for the assessment of HER2 status in breast cancer: an international validation ring study. Breast Cancer Res 9(5):R68

41. McShane LM et al (2006) REporting recommendations for tumor MARKer prognostic studies (REMARK). Breast Cancer Res Treat 100(2):229-235

42. Nishita M et al (2010) Ror2/Frizzled complex mediates Wnt5ainduced AP-1 activation by regulating Dishevelled polymerization. Mol Cell Biol 30(14):3610-3619

43. Gao $S$ et al (2014) Dsh homolog DVL3 mediates resistance to IGFIR inhibition by regulating IGF-RAS signaling. Cancer Res 74(20):5866-5877

44. Hegazy SA et al (2013) Disheveled proteins promote cell growth and tumorigenicity in ALK-positive anaplastic large cell lymphoma. Cell Signal 25(1):295-307
45. Kwan HT et al (2013) AMPK activators suppress cervical cancer cell growth through inhibition of DVL3 mediated Wnt/betacatenin signaling activity. PLoS ONE 8(1):e53597

46. Zhao Y et al (2010) Dishevelled-1 and dishevelled-3 affect cell invasion mainly through canonical and noncanonical Wnt pathway, respectively, and associate with poor prognosis in nonsmall cell lung cancer. Mol Carcinog 49(8):760-770

47. Navarro V et al (2006) Toothbrush-thinking seizures. Epilepsia 47(11):1971-1973

48. Sabol M et al (2014) Surgical management of breast cancer liver metastases. Neoplasma 61(5):601-606

49. Van Cutsem E et al (2014) Metastatic colorectal cancer: ESMO Clinical Practice Guidelines for diagnosis, treatment and followup. Ann Oncol 25(Suppl 3):1-9

50. Bachmeier B et al (2011) Development of resistance towards artesunate in MDA-MB-231 human breast cancer cells. PLoS ONE 6(5):e20550

51. Klemm F, Joyce JA (2014) Microenvironmental regulation of therapeutic response in cancer. Trends Cell Biol 25(4):198-213

52. Devaud C et al (2014) Tissues in different anatomical sites can sculpt and vary the tumor microenvironment to affect responses to therapy. Mol Ther 22(1):18-27

53. Shah SP et al (2009) Mutational evolution in a lobular breast tumour profiled at single nucleotide resolution. Nature 461(7265):809-813

54. Ding L et al (2012) Clonal evolution in relapsed acute myeloid leukaemia revealed by whole-genome sequencing. Nature 481(7382):506-510

55. Kroigard AB et al (2015) Clonal expansion and linear genome evolution through breast cancer progression from pre-invasive stages to asynchronous metastasis. Oncotarget 6(8):5634-5649

56. Brastianos PK, Cahill DP (2015) Management of brain metastases in the era of targeted and immunomodulatory therapies. Oncology 29(4):261-263

57. Saunus JM et al (2015) Integrated genomic and transcriptomic analysis of human brain metastases identifies alterations of potential clinical significance. J Pathol 237(3):363-378

58. Luga $\mathrm{V}$ et al (2012) Exosomes mediate stromal mobilization of autocrine Wnt-PCP signaling in breast cancer cell migration. Cell 151(7):1542-1556

59. Pukrop $\mathrm{T}$ et al (2006) Wnt 5a signaling is critical for macrophage-induced invasion of breast cancer cell lines. Proc Natl Acad Sci USA 103(14):5454-5459

60. Brastianos PK et al (2015) Genomic characterization of brain metastases reveals branched evolution and potential therapeutic targets. Cancer Discov 5(11):1164-1177

61. Paik PK et al (2015) Next-generation sequencing of stage IV squamous cell lung cancers reveals an association of PI3 K aberrations and evidence of clonal heterogeneity in patients with brain metastases. Cancer Discov 5(6):610-621 